\title{
Dental Kişi Tanıma Amacıyla Panoramik Röntgen Görüntülerinde Yeni Bir Çene Bölütleme Yöntemi
}

\author{
Mustafa Hakan Bozkurt ${ }^{*}$, Serap Karagöl ${ }^{2}$ \\ 1* Karadeniz Teknik Üniversitesi, Of Teknoloji Fakültesi, Yazılım Mühendisliği Bölümü, Trabzon, Türkiye (ORCID: 0000-0002-7734-0295), \\ mhakanbozkurt@ktu.edu.tr \\ ${ }^{2}$ Ondokuz Mayı Üniversitesi, Mühendislik Fakültesi, Elektrik Elektronik Mühendisliği Bölümü, İstanbul, Türkiye (ORCID: 0000-0002-5750-1143), \\ serap.karagol@omu.edu.tr
}

(3rd International Congress on Human-Computer Interaction, Optimization and Robotic Applications June 11-13, 2021)

(DOI: 10.31590/ejosat.948468)

ATIF/REFERENCE: Bozkurt, M.H. \& Karagöl, S. (2021). Dental Kişi Tanıma Amacıyla Panoramik Röntgen Görüntülerinde Yeni Bir Çene Bölütleme Yöntemi. Avrupa Bilim ve Teknoloji Dergisi, (26), 78-84.

\section{$\ddot{O} \mathbf{z}$}

Dental biyometri, kişilerin kimliklerinin tespiti için dental bilgilerinin kullanıldı̆̆ı biyometri türüdür. İris, parmak izi, yürüyüş gibi diğer biyometrik özellikler günümüzde kişilerin tanınması amacıyla başarılı bir şekilde kullanılmaktadır. Ancak bu özellikler çeşitli nedenlerle kolayce zarar görebilirler. Örneğin yangın, deprem ve trafik kazası gibi kişinin ağır yaralandığı durumlarda, bu biyometrik özellikler zarar görebilir ve kullanılamaz hale gelebilir. Dişler ise diğer biyometrik özelliklere göre daha dayanıklıdır. Daha zor bozulurlar. Dişlerin bu özelliği sayesinde dental biyometri, diğer biyometrik özelliklerin kullanılabilir olmadığı durumlarda tercih edilmektedir. Dental görüntülemede bitewing, periapikal ve panoramik röntgen gibi farklı yöntemler bulunmaktadır. Bitewing tipi röntgen görüntülerinde çenenin bir bölümünde alt ve üst dişler görüntülenmektedir. Periapikal röntgenler bir ya birkaç dişin detaylı görüntülendiği röntgenlerdir. Panoramik röntgen görüntüleri ise tüm çenenin panoramik bir şekilde görüntülendiği röntgen türüdür. Bu röntgen tipinde tüm dişler bir arada görüntülenmektedir. Panoramik röntgenler çene ve diş yapıları konusunda daha fazla bilgi içermesi yönüyle daha avantajlıdır. Ancak buna karşın panoramik röntgen görüntülerinde, çene ve burun kemiği, ısırma diski gibi istenmeyen öğeler bulunmaktadır. Bu durum görüntülerin işlenmesini zorlaştırmaktadır. Üç röntgen türünün işlenmesinde ortak olarak düşük parlaklık değişimi, üst üste gelen ya da farklı yönelimlerde olan dişler gibi zorluklar bulunmaktadır. Dental radyografi görüntülerinden kişi tanıma uygulamasının ana aşamaları; alt ve üst çene ayrımı, diş ayrımı, özellik çıkarımı ve eşleştirmedir. Bu aşamalardan ilki alt-üst çene segmentasyonudur. Bu aşamanın yüksek doğrulukla yapılması, sonraki aşamaları da etkilemektedir. $\mathrm{Bu}$ nedenle çene ayırma işleminin en az hata ile tamamlanması önemlidir. Bu çalışmada panoramik röntgen görüntülerinde, alt ve üst çene segmentasyonu için yeni bir yöntem önerilmiştir. Önerilen yöntem ile kullanılan veri tabanında yüksek doğruluk ile çene ayırma işlemi gerçekleştirilmiştir. Kıyaslanan güncel diğer çalışmalara göre daha yüksek doğruluk oranı elde edilmiştir.

Anahtar Kelimeler: dental kişi tanıma, bölütleme, medikal görüntüleme, görüntü işleme, biyometri.

\section{A New Jaw Segmentation Method on Panoramic X-Ray Images for Dental Human Identification}

\footnotetext{
Abstract

Dental biometry is a biometry method in which dental information is used to identify individuals. Other biometric features such as iris, fingerprints, and gait are successfully used today to identify people. However, these features can be easily damaged for various reasons.

* Sorumlu Yazar: Karadeniz Teknik Üniversitesi, Of Teknoloji Fakültesi, Yazılım Mühendisliği Bölümü, Trabzon, Türkiye, ORCID: 0000-0002-77340295, $\underline{\text { mhakanbozkurt@ktu.edu.tr }}$
} 
For example, these biometric properties can be damaged and become unusable in cases of heavy damage such as fire, earthquake and traffic accident. Teeth are more durable than other biometric features. They deteriorate more difficultly. Thanks to this feature of teeth, dental biometry is preferred when other biometric features are not available. There are different methods in dental imaging such as bitewing, periapical and panoramic $\mathrm{x}$-ray. Bitewing type $\mathrm{x}$-ray images shows the upper and lower teeth in a part of the jaw. Periapical $\mathrm{X}$-rays are X-rays that show one or more teeth in detail. Periapical X-rays are images that are shown one or more teeth in detail. Panoramic $\mathrm{x}$-ray images, on the other hand, are a type of $\mathrm{x}$-ray in which the entire jaw is viewed in a panoramic way. In this type of $\mathrm{x}$ ray, all teeth are displayed together. Panoramic x-rays are more advantageous in that they contain more information about jaw and tooth structures. However, panoramic x-ray images contain undesirable items such as jawbone, nasal bone and bite disc. This situation makes it difficult to process images. Common difficulties in processing the three X-ray types are low brightness variation, overlapping teeth or teeth with different orientations. Main stages of person recognition application from dental radiography images are lower and upper jaw separation, tooth separation, feature extraction and matching. The first of these stages is the lower upper jaw segmentation. Failure to do this stage with high accuracy affects the next stages as well. For this reason, it is important to complete the jaw separation process with the least error. In this study, a new method is proposed for upper and lower jaw segmentation in panoramic X-ray images. With the proposed method, jaw separation was performed with high accuracy in the database used. In addition, higher accuracy rate was achieved compared to other compared current studies.

Keywords: dental human identification, segmentation, medical imaging, image processing, biometrics.

\section{Giriş}

Kişilerin, bireysel karakteristik özelliklerine göre tanımlanması için oluşturulmuş sistemler biyometrik sistemler olarak adlandırılmaktadır. Kişilerin tanınması amacıyla çeşitli farklı biyometrik özellikler kullanılabilmektedir: Parmak izi, yüz, ses, göz ve yazı bilinen ve sıkça kullanılan biyometrik özelliklerden bazılarıdır. Bu özelliklerden faydalanılarak yüksek başarı ile kişi tanıma işlemleri gerçekleştirilebilmektedir. Buna karşın bir kaza durumunda bu özellikler kolayca zarar görebilir ve bozulabilirler. $\mathrm{Bu}$ nedenle yangın ve deprem gibi vücudun ağır zarar gördüğü bir ölüm sonrasında, kişi tespiti konusunda bu biyometrik özellikler kullanılamayabilir. Dişler ise diğer biyometrik özelliklerin elde edildiği organlara kıyasla daha dayanıklıdır. $\mathrm{Bu}$ da dişleri ağır yaralanmalı kaza durumlarında diğer özelliklere göre daha kullanılabilir kılmaktadır. $\mathrm{Bu}$ özellikleri nedeniyle diğer özelliklerin kullanılamadığı durumlarda kişi tespiti; adli diş bilimcileri tarafindan, ağız ve diş özellikleri incelenerek yapılmaktadır (Pretty ve Sweet, 2001). Adli diş hekimleri tarafinda elle yapılan bu işlem uzun ve zordur. $\mathrm{Bu}$ işlemlerin bilgisayar yardımı ile yapılması adli diş hekimine yardımcı olacak ve süreci hızlandıracaktır.

Panoramik radyografi görüntüleri ağzın tamamının panoramik olarak görüntülendiği röntgenlerdir. Bu görüntülerden diş ve kemik anomalileri, kist, tümör ve enfeksiyon gibi çeşitli hastalıkların gözlemlenmesi amacıyla faydalanılmaktadır (Silva ve ark., 2018). Dental rahatsızlıklarda sıkça faydalanılan panoramik radyografi görüntüleri tüm dişleri ve çene yapısını birlikte içermesi işlenmelerini zorlaştırmaktadır, ancak dental özellikleri bitewing ve periapikal görüntülere göre daha çok içermeleri nedeniyle avantajlıdırlar.

Kişi tanıma işleminin ana aşamalarından birisi segmentasyondur. Dental görüntülerin segmentasyonunda çene ve dişlerin ayrıştırılması amaçlanır. Böylece özellik çıkarımına uygun hale gelirler.

Dental radyografi görüntülerinde parlaklık değişimlerinin yetersiz kalabilmesi, gürültüden kolay etkilenebilmeleri, dişler üzerindeki tedaviler, kırık ya da üst üste gelen dişlerin bulunması gibi nedenlerden ötürü zordur.

Kişi tanıma amacıyla dental radyografi segmentasyonu için literatürde çeşitli yöntemler bulunmaktadır. Bu çalışmalarda graf tabanlı (Barboza ve ark., 2012, Nomir ve ark., 2012), yarı otomatik (Jain ve ark., 2003, Bozkurt ve Karagöl, 2020), eşikleme (Abdel-Mottaleb ve ark., 2003), parlaklık izdüşümü (Jain ve Chen, 2004, Frejlichowski ve Wanat, 2011b, Oktay 2017, Ølberg ve Goodwin, 2016), aktif kontur modeli (Chen ve Jain 2004), bağlantılı bileşenler (Said ve ark., 2006), havza (Frejlichowski ve Wanat, 2011a), PHOG (Oktay,2017), maske (Dibeh ve ark. 2018), PSO (Bozkurt ve Karagöl, 2020) gibi yöntemlerden faydalanılmıştır.

Önerilen algoritmalar başarıyla çalışıyor olsa da ortak bir veri tabanı olmaması nedeni ile farklı veri tabanlarında farkl performanslar elde ediliyor olması; henüz istenilen başarıya ulaşılamamış olması, ayrıca çalışmaların çoğunun panoramik röntgenler için hazırlanmamış olması gibi nedenlerden bu alanda güncel çalışmalara ihtiyaç duyulmaktadır.

Bu çalışmada panoramik röntgen görüntülerinde kişi tanıma amacıyla yeni bir çene segmentasyon yöntemi önerilmiştir. Literatürde çene ayrımı için parlaklık izdüşümü (Jain ve Chen, 2004), parçacık sürü optimizasyonu (Bozkurt ve Karagöl, 2020) ve en k1sa yol (Ølberg ve Goodwin, 2016) gibi yöntemler önerilmiştir. Parlaklık izdüşümü yöntemi ilk olarak bitewing tipi görüntülere uygulanmıştır. Ancak sonraki yıllarda panoramik görüntülere uygulanabilecek şekilde modifiye edilerek (Frejlichowski ve Wanat, 2011b, Oktay 2017) kullanılmaktadır. En k1sa yol yöntemi (Ølberg ve Goodwin, 2016) sadece bitewing görüntüler için önerilmiştir. Çembersel maske yaklaşımı (Dibeh ve ark., 2018) ile PSO yaklaşımı PSO (Bozkurt ve Karagöl, 2020) ise panoramik röntgen görüntülerinde çene ayrım eğrisinin otomatik olarak belirlenmesi amacıyla sunulan güncel diğer çalışmalardır. Önerilen çalışma panoramic röntgen görüntülerine uygun şekilde hazırlanmış güncel çalışmalarla (Oktay 2017, Dibeh ve ark., 2018, Bozkurt ve Karagöl, 2020) kıyaslanmıştır.

Önerilen yöntem ile kıyaslanan diğer çene ayrım yöntemlerine göre daha başarılı çene ayrımı gerçekleştirilmiştir.

\section{Materyal ve Metot}

Bu çalışmada veri seti olarak Gil Silva ve arkadaşlarının sunmuş oldukları veri tabanı (Silva ve ark., 2018) kullanılmıştır. Veri seti; 1991x1127 boyutlarındaki panoramik diş röntgen görüntülerinden oluşmaktadır. Röntgen görüntüleri ORTHOPHOS XG 5/XG 5 DS/Ceph modeli X-ray kamerasından alınmış olup başlangıçta 2440x1292 piksel boyutunda olan görüntülerin hepsinde çene harici arka plan kısımları kırpılmıştır. 
Panoramik röntgen görüntüleri dişlerin yanı sıra çene kemiği, burun kemiği gibi farklı yapılar da içermektedir. Bu yapılar çene ve diş ayırma işlemlerini zorlaştırmaktadır. Bu nedenle önerilen yöntem; görüntünün çene boşluğunun yaklaşık bir konumunu belirlemeye ve bu konum etrafinda arama yapmaya dayanmaktadır. Temel işlem adımları Şekil 1'de gösterilmiştir. Görüntü ilk olarak çene boşluğunu belirlemeye yönelik bir ön işlemeden geçirilmektedir. Bu ön işleme ile parlaklık dağılımının daha düzgün olması amaçlanmaktadır. Bununla birlikte diş arası boşluklar ve diş pulpaları arama yaparken yanlış noktalara ilerlemeye neden olabilmektedir. $\mathrm{Bu}$ nedenle ön işleme ile bu boşluklar da giderilmeye çalışılmaktadır.

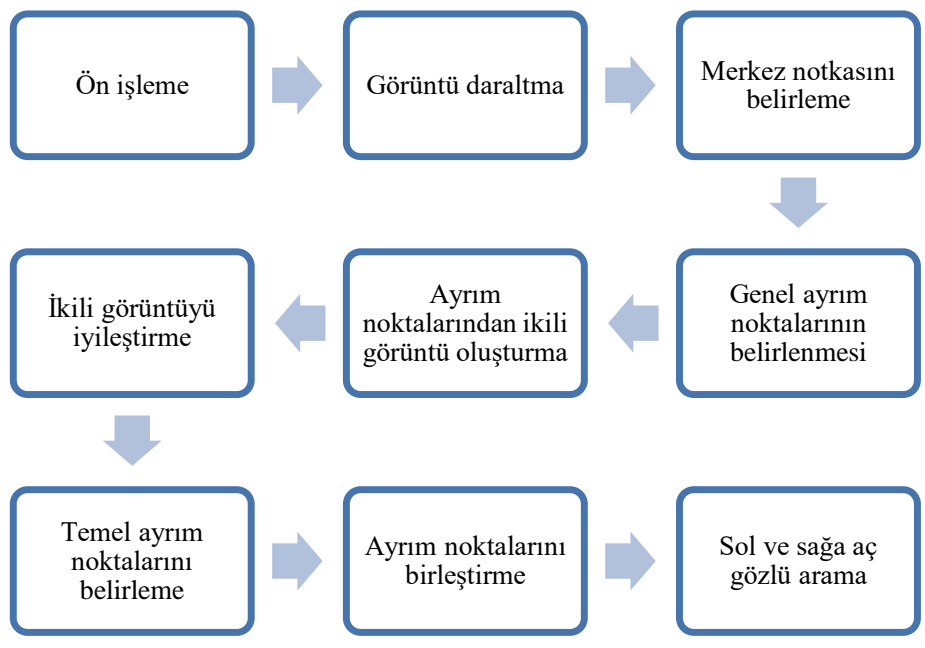

\section{Şekil 1. Yöntem akışı}

Ön işleme amaciyla ilk olarak görüntü üzerinde gri seviyeye dönüşüm ile başlamaktadır. Ardından diş arası boşlukları ve diş pulpalarını elimine etmek için morfolojik dilezyon işlemi uygulanmaktadır. Bu işlemi yaparken amaç yüksek parlaklaklıklı konumlara bitişik düşük parlaklıklı bölgeleri değiştirmektir. Bu nedenle yapısal eleman sadece yatay açıda etki edecek şekilde seçilmiştir. Morfolojik dilezyondan sonra görüntüde histogram eşitleme kullanılarak kontrast iyileştirmesi yapılmaktadır. Son olarak iki boyutlu istatistik filtresi uygulanmaktadır. Bu filtrede $3 * 3$ komşulukta minimum değerler seçilmektedir. Orijinal görüntü ve ön işleme sonucu Şekil 2.'de gösterilmiştir.

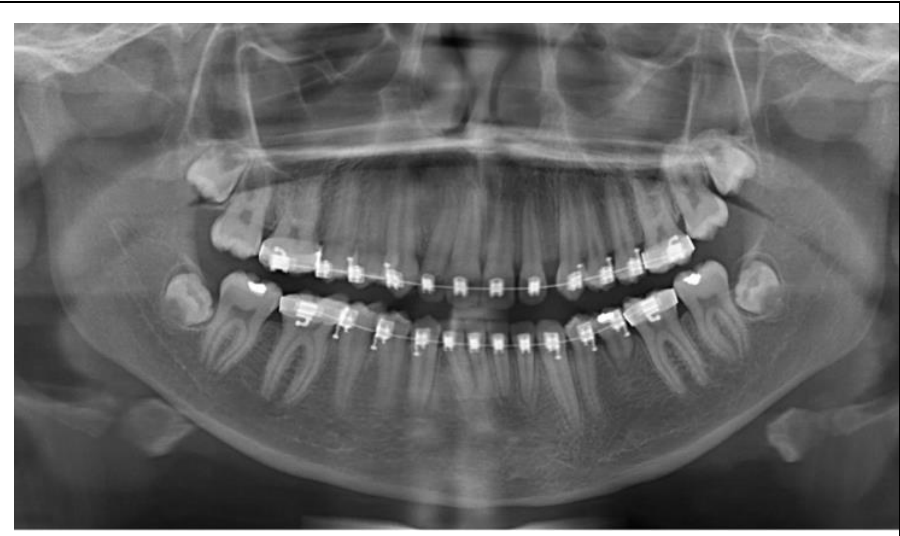

(a)

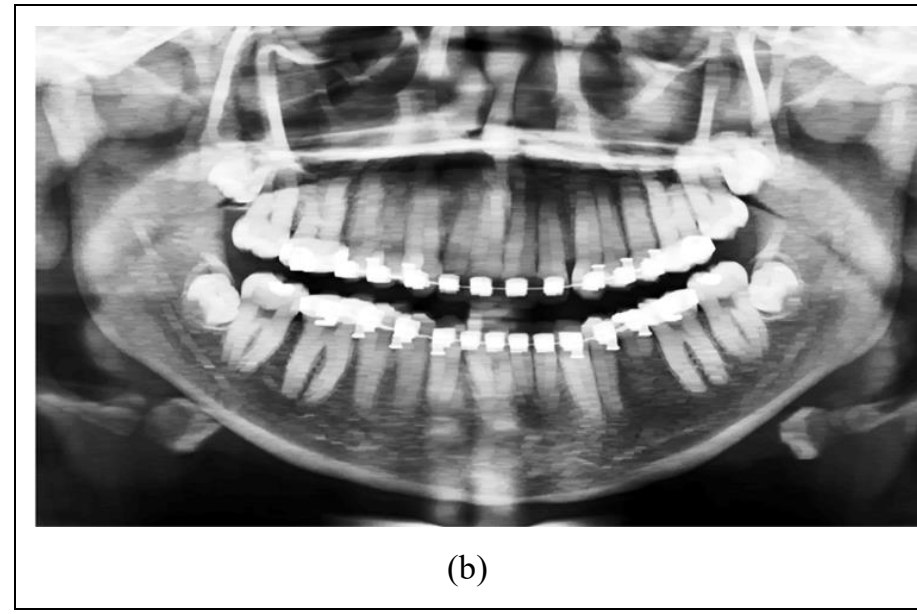

Şekil 2. a) Orjinal görüntü, b) Önişleme sonrasl görüntü

\section{1. Çene Boşluğu Doğrusunun Bulunması}

Ön işleme sonrası ikinci hedef olarak çene boşluğunun (gap valley) yaklaşık konumu belirlenmektedir. $\mathrm{Bu}$ amaçla parlaklık projeksiyonu yönteminden faydalanılmaktadır. Genellikle bitewing tipi görüntülerde uygulanan bu yöntem panoramik görüntülere doğrudan uygulandığında sıklıkla yanlış sonuçlar vermektedir. Bunun nedeni üst çene ile burun arası ve alt çene ile görüntünün sonu arası gibi çene arası kadar koyu renkte bölgelerin bulunmasıdır. Dolayısıyla doğru konumun belirleyebilmek için arama bölgesini daraltmak gerekmektedir. Bu amaçla ilk olarak görüntü üst ve alttan 30\% daraltılmaktadır. Daraltılmış görüntü örneği Şekil 3.'te gösterilmiştir. Kullanılan veri setinde çene boşluğunun, genellikle daraltılan bu bölgede bulunduğu deneysel olarak tespit edilmiştir. İkinci olarak yanlardaki çeneye ait bölgelerin ve röntgen çekimi esnasında 1sırılan diskin etkisini azaltmak için parlaklık projeksiyonu görüntünün yataydaki 1/4-2/4'lük bölgesine uygulanmıştır.

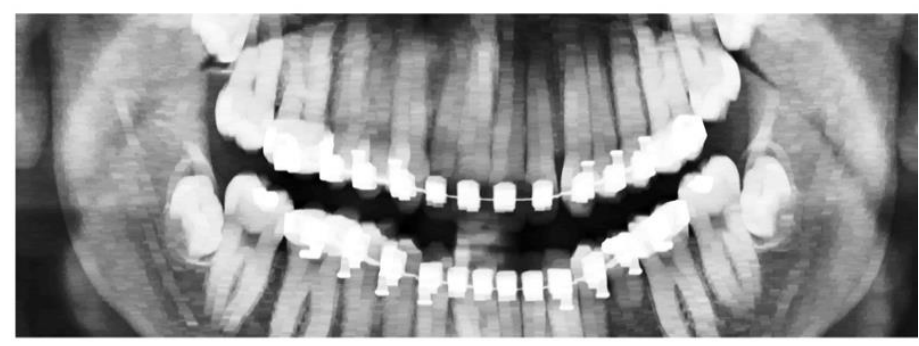

\section{Şekil 3. Üstten ve alttan daraltılmış çene görüntüsü}

Önceki çalışmalarda genellikle parlaklık projeksiyonunun minimum değeri kullanılmaktadır. $\mathrm{Bu}$ durum bitewing tipi görüntüler için iyi sonuç verse de panoramik görüntülerde yetersiz kalmaktadır. Bunun için diğer yöntemlerden farklı olarak pik değerleri kullanılmıştır. $\mathrm{Bu}$ yöntemde parlaklık projeksiyonundaki minimum değerli pikler en az 20 birim mesafe ile belirlenmekte ardından bu pikler içinden maksimum prominansa sahip pik noktası seçilmektedir. Bu nokta merkez çizgi olarak adlandırılmıştır. Burada çene arası boşluğun diğer yerlerdeki yerel boşluklara göre geniş olmasından faydalanılmaktadır. Şekil 4.'te bulunan pik noktaları ve merkez çizgi olarak seçilen pik noktası gösterilmiştir. 


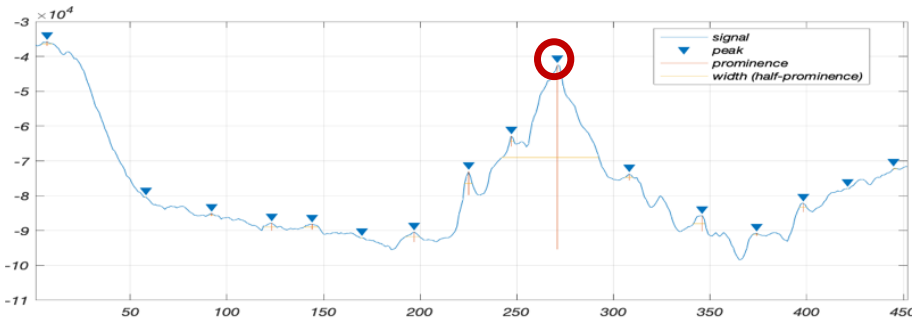

Şekil 4. Maksimum prominans değerine sahip pik

$\mathrm{Bu}$ nokta merkez çizgi olarak adlandırılmıştır. Burada çene arası boşluğun diğer yerlerdeki yerel boşluklara göre geniş olmasından faydalanılmaktadır. Şekil 4.'te bulunan pik noktaları ve merkez çizgi olarak seçilen pik noktası gösterilmiştir.

\subsection{1. Çene ayırma ĕgrisinin oluşturulması}

Belirlenen bu konum çene boşluğundan geçiyor olsa da panoramik görüntülerdeki çene boşluğu yay biçiminde olduğundan çene ayırma için yetersizdir. Bu nedenle merkez çizgi etrafında çeneleri daha iyi ayıran noktaların belirlenmesi gerekmektedir. $\mathrm{Bu}$ noktalar belirlemek için şu yaklaşım uygulanmıştır. Öncelikle çenenin sol ve sağında bulunan koyu pikseller algoritmayı yanlış yönlendirebileceği için bu kısımların atılması gerekmektedir. Bu kısımları elemek için dikey parlaklık projeksiyonu üzerinden en az 20 piksel aralık ile maksimum pikler belirlenir. $\mathrm{Bu}$ piklerden sol ve sağdaki maksimum prominansa sahip konumlar, yataydaki daraltma konumları olarak seçilirler. Sağ ve soldan daraltma için seçilen pik noktaları Şekil 5.'te gösterilmiştir.

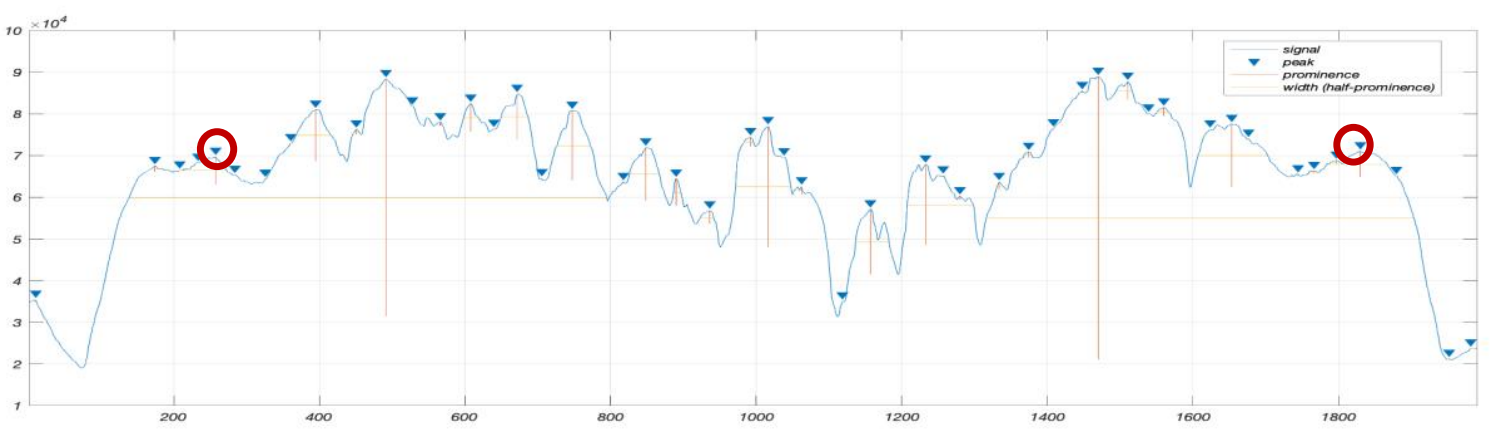

Şekil 5. Sağ ve soldan daraltma için seçilen pik noktaları

Elde daraltılmış görüntü ayırma algoritmasında işlenecek olan görüntüdür. Örnek daraltılmış görüntü Şekil 6.'de gösterilmiştir.

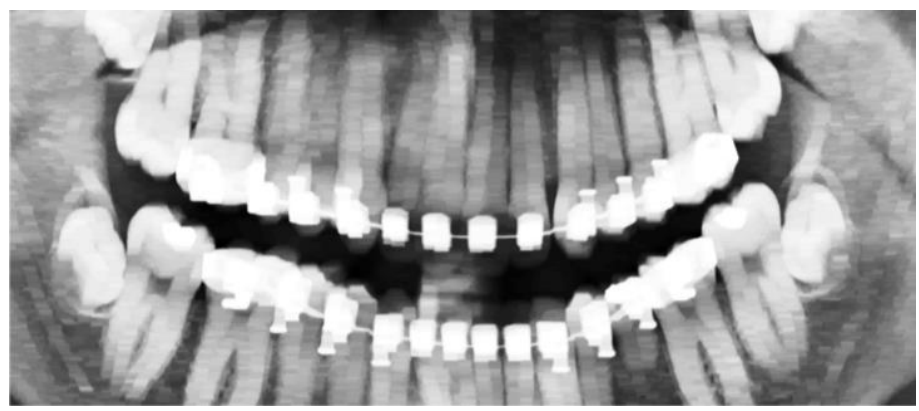

Şekil 6. Să̆ ve soldan daraltılmış örnek çene görüntüsü

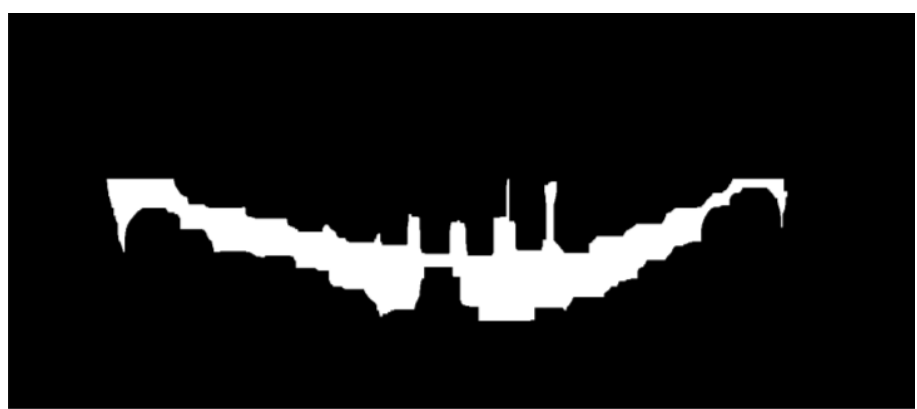

Şekil 7. İkili görüntünün iyileştirilmiş hali
Ayırma için ilk olarak bir referans parlaklık değeri belirlenmektedir. Bunun için merkez çizginin üzerinden geçtiği piksellerin parlaklık değerlerinin ortalaması alınır. Bu çizgi koyu pikseller kadar parlak pikseller üzerinden de geçtiği için referans parlaklık değeri olarak ortalama değerin yarısı kullanılmıştır. Sonra merkez çizgiden itibaren 80 piksel ileri ve 80 piksel gerideki bütün pikseller bu referans parlaklığa göre kontrol edilir. Parlaklık değeri referans parlaklık değerinden düşük olan pikseller 1 diğer pikseller 0 olarak işaretlenir ve bu değerler ile yeni bir görüntü oluşturulur.

Bulunan 1 değerli konumların bir kısmı dişlerin arasında bulunmaktadır. $\mathrm{Bu}$ nedenler yeni görüntü üzerinde morfolojik işlemler yaparak çene arasına ait olmayanlar elenir. Ayrıca 1 değerli konumlar arasındaki küçük boşluklar da elenmektedir. Bu da çene arası boşluğun daha doğru belirlenmesi için faydalıdır. $\mathrm{Bu}$ işlemler için sırasıyla 1000 pikselden küçük nesnelerin silinmesi ve morfolojik kapama uygulamaları yapılmıştır. Uygulanan işlemlerin sonucu Şekil 7.' de görülmektedir.

Son olarak elde edilen görüntü üzerinde çeneler arası boşluğa ait noktalar bulunmaktadır. Ayrıca bu noktalar içerisinde hala elenememiş küçük piksel grupları da bulunabilmektedir. Bu nedenle ilgili piksel grubundan en iyi ayıran noktaları seçmek için her bir sütundaki merkez çizgiye en yakın satırdaki noktalar belirlenir. $\mathrm{Bu}$ sayede üst diş aralarına doğru gruplanmış piksellerde alttaki; alt diş aralarına doğru gruplanmış piksellerde üstteki noktaların seçilmesi sağlanır. Bu da çeneyi daha iyi ayırmayı sağlamaktadır.

Son durumda seçilen noktaların arasında eksik olanlar bulunabilmektedir. Eksik noktaları bulmak için her bir sütundaki 
orta noktaya en yakın olan sütundaki nokta belirlenir. $\mathrm{Bu}$ noktaların sütun değerleri arasındaki fark birden fazla ise bu iki nokta ile bir doğru oluşturulur ve aradaki noktalar bu doğru üzerinden elde edilir. Bu işlem ile çene arasında çeneyi en iyi ayıran en iyi noktalar belirlenmiş olur.

\subsubsection{Kenar Bölgelerdeki Ayrım Noktalarının Bulunması}

Seçilen noktaların en sol ve en sağı görüntünün en solu ve en sağında değildir. Çünkü en sol ve en sağda çene kemiği bulunmaktadır. Çene kemiğine yakın piksellerin parlaklık değerleri de yüksek olduğundan bu kısımlar da seçilmeyebilmektedir. Dolayısıyla, bu noktalardan görüntünün sol ve sağına doğru ayırma noktalarının da belirlenmesi gerekmektedir. İlgili noktaları belirlemek için belirlenmiş ayırma noktalarının en sol ve en sağından aç gözlü arama yapılmıştır. Aç gözlü arama için her bir noktanın sütun komşuluğundaki en yakın satırlardaki 7 nokta belirlenir. Bu 7 noktadan en düşük parlaklık değerine sahip piksel yeni en sol ya da en sağ piksel olarak seçilir. Bu şekilde görüntünün soluna kadar devam edilir. Son olarak sağ ve soldan daraltılmış kısımlarda ayırım konumlar seçilmiştir. Bu kısımlar çenelere denk geldiği için bir arama işlemi yapmak yerine en yakındaki ile aynı satırda devam edilerek görüntünün sonuna ulaşıllmaktadır.

Kenar bölgelerde elde edilen noktalar daha önce belirlenen çene ayırma noktaları ile birleştirilir. Elde edilen bu toplam nokta verileri üzerinde yumuşatma yapılır böylece daha yumuşak geçişleri olan bir ayırma eğrisi elde edilmiş olur.

\section{Araştırma Sonuçları ve Tartışma}

\subsection{Deneysel Sonuçlar}

Çalışmanın performans ölçüm için bir program hazırlanmıştır. Program Mac platformunda Matlab ortamında hazırlanmıştır.

Programda çene ayrım eğrileri Şekil 8'daki gibi gösterilmiştir.

Çene ayrım işlemi sonucunda doğru şekilde ayrılmış olan diş sayılarının kıyaslanması ve doğruluk başarıları Şekil 9.'da verilmiştir.

Tablo 1.'de 32 adet dişin başarı ile ayrılma oranlarının ortalaması gösterilmiştrir.

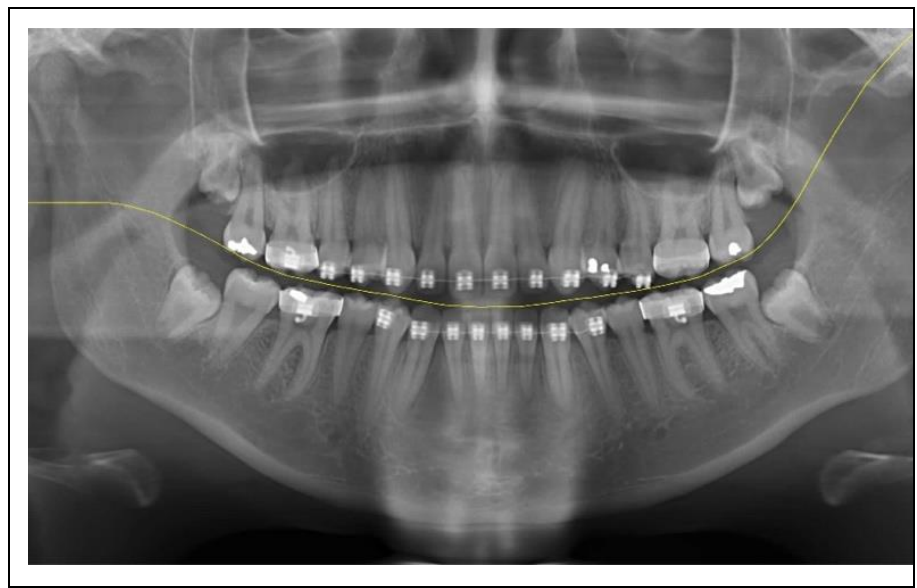

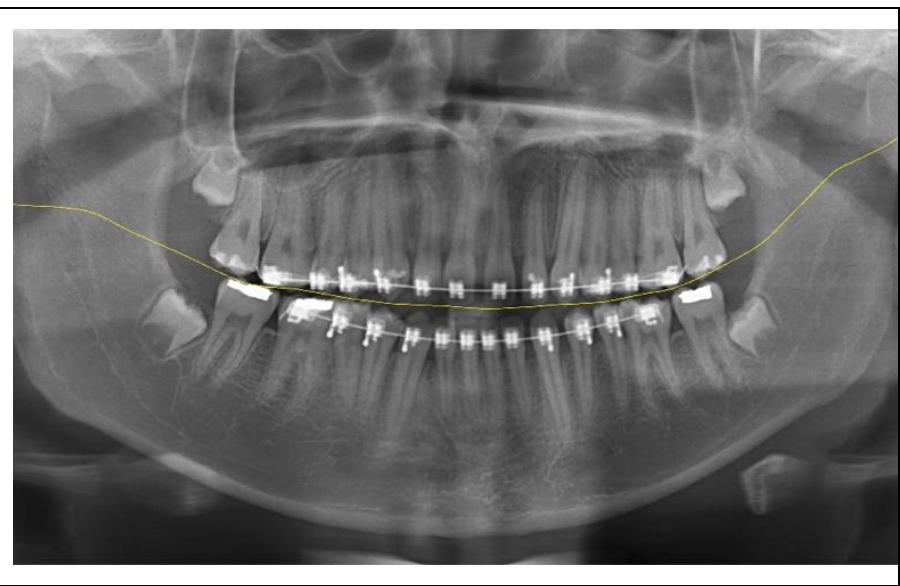
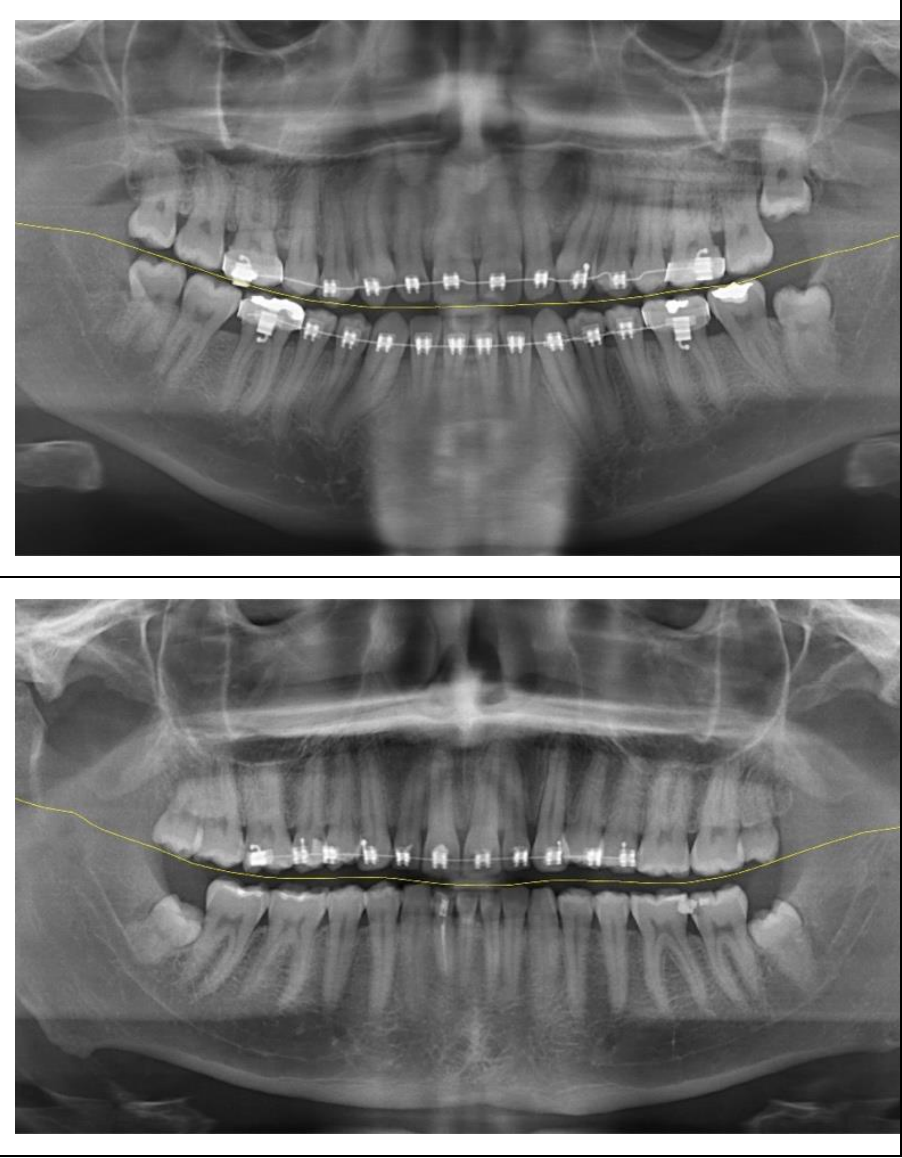

Şekil 8. Örnek çene ayrım sonuçları 


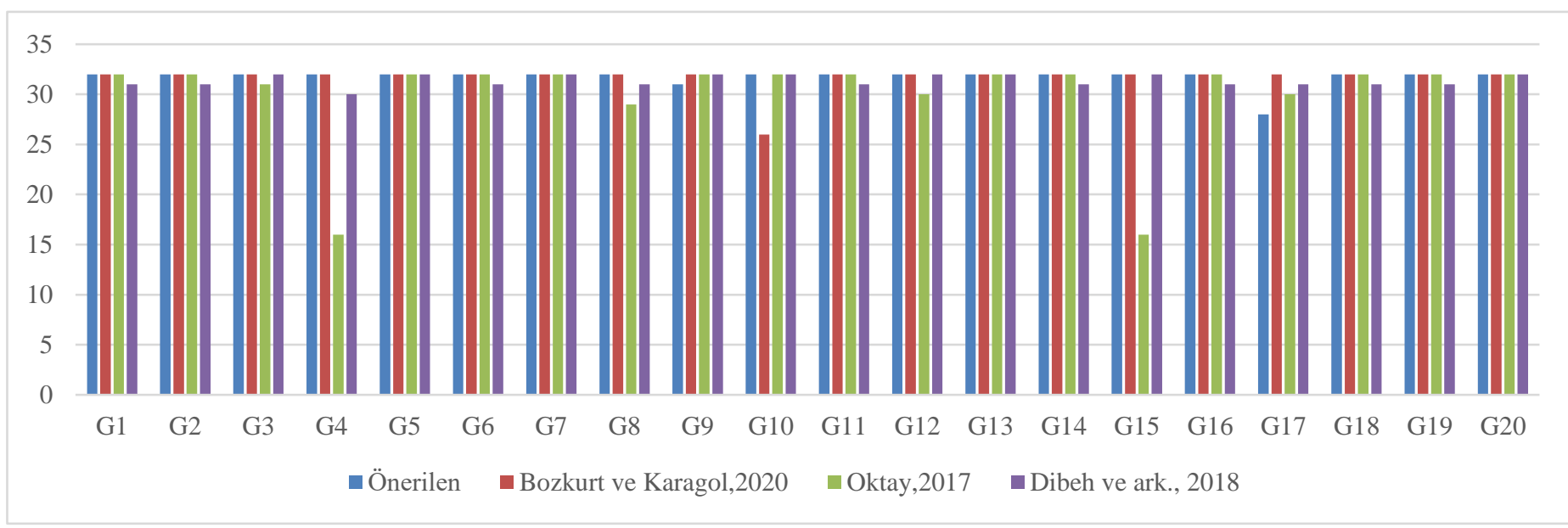

Şekil 9. Çene ayrım işlemi sonucunda doğru şekilde ayrılmış olan dişs sayılarının kıyaslanması

Tablo 1. Diş ayrım oranları ve doğruluk sonuçları

\begin{tabular}{|c|c|c|c|c|}
\hline Çalışma & Önerilen & Bozkurt ve Karagöl, 2020 & Oktay,2017 & Dibeh ve Ark. 2018 \\
\hline Ortalama (Maks:32) & 31,75 & 31,7 & 30 & 31,4 \\
\hline Doğruluk & 0,9921875 & 0,990625 & 0,9375 & 0,98125 \\
\hline
\end{tabular}

\subsection{Tartışma ve Gelecek Çalışma}

Panoramik röntgen görüntüleri çene ve burun kemiği gibi farklı kısımlar içermektedir. Bu kısımlar yapıları nedeniyle farklı parlaklık düzeylerinde algılanırlar. Dokular nedeni ile oluşan gürültüler, ısırma diski ve kemikler arası boşluklar çene ve diş ayırma işlemlerini zorlaştırmaktadır. Önerilen yöntem çeneler arası ayırma çizgisini belirlemekte ve belirlediği bölge çevresinde eşikleme yardımı ile çenelerarası boşluğa ait pikselleri oluşturmaktadır. Sonuçlar incelendiğinde yöntemin diş telleri gibi parlak kısımlar içeren bölümlerde daha net şekilde ayrım yapabildiği görülmüştür. Ayrım doğrusu belirlenirken ısırma diski ve kemiklerden etkilenmemesi için parlaklık izdüşümü görüntünün yatayda 1/4-2/4 'lük dilimleri arasından elde edilmektedir. Bu sayede iyi bir ayrım konumu belirlenmeye çalışılmaktadır. Ancak ısırma diskinin bulunduğu bölgelerde ayırma doğrusunun çoğunlukla yukarıya yakın olmasına neden olmaktadır. Gelecek çalışmalarda görüntü birden fazla bölge üzerinde incelenerek daha iyi bir ayırma işlemi yapılacaktır.

\section{Sonuç}

Diş görüntülerinden kişi tanıma; diğer biyometrik özelliklerin kullanılamaz hale geldiği durumlarda, ölüm sonrası kişilerin tespiti için yapılmaktadır. Bu işlem bir adli diş uzmanı tarafindan elle yapılmaktadır. Bilgisayar yardımı ile dental benzerliklerin ölçülmesi bu süreçte adli diş hekimine yardımcı olacaktır. Bilgisayar yardımı ile dental radyografi görüntülerinden kişi tanımanın anahtar aşamalarından birisi segmentasyon aşamasıdır. Segmentasyonun başarısı özellik çıkarımı ve eşleş̧irme kısımlarının da başarısını etkileyeceğinden, yüksek başarı ile bölütleme önemlidir.

$\mathrm{Bu}$ çalışmada panoramik diş röntgen görüntülerinin bölütlenmesi için yeni bir çene ayırma yöntemi önerilmiştir. Çalışmada parlaklık projeksiyonunun belirli bir bölgede yapılarak bir ayırma doğrusu belirlenmiştir. Bu ayırma doğrusu etrafında eşikleme yaparak çene ayırım boşluğu bölgesi oluşturulur. $\mathrm{Bu}$ bölge ve ayırma doğrusu konumlarından yararlanarak en iyi ayrım eğrisi belirlenmeye çalışılmıştır. Son olarak kenar kısımlarda ayrım noktaları aç gözlü algoritma ile bulunmuştur.
Önerilen çalışma ile diğer çalışmalara göre daha yüksek doğruluk başarısı sunulmaktadır.

\section{Kaynakça}

Pretty, I. A., \& Sweet, D. (2001). A look at forensic dentistry-Part 1: The role of teeth in the determination of human identity. British dental journal, 190(7), 359-366.

Silva, G., Oliveira, L., \& Pithon, M. (2018). Automatic segmenting teeth in X-ray images: Trends, a novel data set, benchmarking and future perspectives. Expert Systems with Applications, 107, 15-31.

Barboza, E. B., Marana, A. N., \& Oliveira, D. T. (2012, March). Semiautomatic dental recognition using a graph-based segmentation algorithm and teeth shapes features. In 2012 5th IAPR International Conference on Biometrics (ICB) (pp. 348353). IEEE.

Nomir, O. (2012). Human Identification: A new x-Ray Dental Radiographs Segmentation Algorithm using Graphcut. International Journal of Computers and Applications, 34(2), 81-89.

Jain, A. K., Chen, H., \& Minut, S. (2003, June). Dental biometrics: human identification using dental radiographs. In 
International Conference on Audio-and Video-Based Biometric Person Authentication (pp. 429-437). Springer, Berlin, Heidelberg.

Abdel-Mottaleb, M., Nomir, O., Nassar, D. E., Fahmy, G., \& Ammar, H. H. (2003, December). Challenges of developing an automated dental identification system. In 2003 46th Midwest Symposium on Circuits and Systems (Vol. 1, pp. 411-414). IEEE.

Jain, A. K., \& Chen, H. (2004). Matching of dental X-ray images for human identification. Pattern recognition, 37(7), 15191532.

Chen, H., \& Jain, A. K. (2004, August). Tooth contour extraction for matching dental radiographs. In Proceedings of the 17th International Conference on Pattern Recognition, 2004. ICPR 2004. (Vol. 3, pp. 522-525). IEEE.

Bozkurt, M. H., \& Karagol, S. (2020). Jaw and teeth segmentation on the panoramic X-ray images for dental human identification. Journal of Digital Imaging, 33(6), 1410-1427.

Said, E. H., Nassar, D. E. M., Fahmy, G., \& Ammar, H. H. (2006). Teeth segmentation in digitized dental X-ray films using mathematical morphology. IEEE transactions on information forensics and security, 1(2), 178-189.

Ølberg, J. V., \& Goodwin, M. (2016). Automated dental identification with lowest cost path-based teeth and jaw separation. Scandinavian Journal of Forensic Science, 22(2), 44-56.

Frejlichowski, D., \& Wanat, R. (2011, August). Extraction of teeth shapes from orthopantomograms for forensic human identification. In International Conference on Computer Analysis of Images and Patterns (pp. 65-72). Springer, Berlin, Heidelberg.

Dibeh, G., Hilal, A., \& Charara, J. (2018, November). A novel approach for dental panoramic radiograph segmentation. In 2018 IEEE International Multidisciplinary Conference on Engineering Technology (IMCET) (pp. 1-6). IEEE.

Oktay, A. B. (2017). Human identification with dental panoramic radiographic images. IET Biometrics, 7(4), 349-355. 